\title{
Evaluation of mathematical models to describe growth of grazing young bulls ${ }^{1}$
}

\author{
Henrique Jorge Fernandes ${ }^{2,3}$, Luis Orlindo Tedeschi ${ }^{4}$, Mário Fonseca Paulino ${ }^{3}$, Edenio \\ Detmann $^{3}$, Luisa Melville Paiva ${ }^{2,3}$, Sebastião de Campos Valadares Filho ${ }^{3}$, Aline Gomes da \\ Silva ${ }^{3}$, José Augusto Gomes Azevêdo ${ }^{3,5}$
}

\author{
${ }^{1}$ Research partially funded by FAPEMIG and CNPq. \\ 2 Universidade Estadual de Mato Grosso do Sul, UEMS/Unidade de Aquidauana. Scholar from FUNDECT/MS. \\ 3 Universidade Federal de Viçosa, Departamento de Zootecnia - DZO/UFV. \\ ${ }^{4}$ Texas A\&M University, Department of Animal Science. \\ ${ }^{5}$ Universidade Estadual de Santa Cruz, UESC.
}

\begin{abstract}
The objective of this study was to evaluate the use of different mathematical models to describe growth of grazing beef cattle. Data of 20 Nellore bulls with initial weight of $129 \pm 28.1 \mathrm{~kg}$ and final weight of $405 \pm 62.0 \mathrm{~kg}$ were used. The animals were randomly divided into four plots and placed on B. decumbens Stapf pastures. Three plots received concentrate supplement with different protein profiles and the fourth plot received only mineral supplement. Animals were weighed every 28 days to design growth curve of full body weight. Five mathematical models were evaluated to describe animal growth: Multiphase, Linear, Logarithmic, Gompertz and Logistic models. Assessment of adequacy of the models was performed by using coefficient of determination, simultaneous $F$-test for identity of parameters, concordance correlation coefficient, root of the mean square error of prediction and partition of the mean square error of prediction. The analysis of the pairwise mean square error of prediction and the delta Akaike's information criterion were used to compare the models for accuracy and precision. Evaluation of all the tested models showed that all of them were able to predict variability among animals. However, Gompertz, Logarithmic and Logistic models created individual predictions that were not satisfactory. Models differed from each other concerning accuracy and precision; the best were in the following order: Multiphase, Linear, Gompertz, Logarithmic and Logistic. The Multiphase model was more efficient than the others for description of grazing beef cattle growth.
\end{abstract}

Key Words: grazing beef cattle, modeling, seasonality

\section{Introduction}

The primary function of a mathematical model is to provide the best depiction of the phenomenon one wants to describe (Thornley \& France, 2007). So, when animal growth is studied, growth models should be fitted to the situation in which they will be applied. After genetics define animal growth curve, life phase and environmental factors respond for the variations in its growth pattern (Berg \& Butterfield, 1976; Lawrence \& Fowler, 2002). Thus, it is important to take into account the effects of seasonal variability of forage nutrients in the studies of grazing cattle under tropical conditions.

The use of multiphase models was suggested by Berg \& Butterfield (1976) out of the available mathematical options to overcome difficulties of fitting mathematical models to animal growth patterns. Another advantage of this model is its greater capacity of obtaining information on animal growth from the estimated parameters. On the other hand, Lawrence \& Fowler (2002) stated that when short periods of time are evaluated in relation to normal life of the animals, growth can behave according to a linear model. Gompertz and logistic models are part of a non-linear models "family", used for a long time to describe living being growth (Thornley \& France, 2007), and they are the ones most used to describe cattle growth curve in Brazil (Garnero, 2005). Finally, the logarithm transformed model has been perhaps the most used in the last years to describe allometric growth of body components, especially in experiments which evaluated animal body composition as suggested by the ARC (1980).

The objective of this study was to evaluate the capacity of different mathematical models to describe the growth of Nellore beef cattle raised in tropical pastures.

\section{Material and Methods}

Data from an experiment carried out from March 2007 to April 2008 in the beef cattle sector of Universidade Federal de Viçosa were used. In this experiment, 20 bulls with genetic composition of at least $50 \%$ of Nellore breed and initial weight of $129 \pm 28.1 \mathrm{~kg}$ at $130 \pm 30.1$ days of age and average final weight of $405 \pm 62.0 \mathrm{~kg}$ were used. 
At the beginning of the experiment, animals were randomly divided into four plots and placed on B. decumbens Stapf pastures. Three plots were supplied with one of the concentrate supplements composed of corn, soybean meal and urea formulated according to recommendations of the NRC (2000), and $1.2 \mathrm{~kg} / \mathrm{d}$ (lactation period, rainy/dry transition season, from March to April); $1.5 \mathrm{~kg} / \mathrm{d}$ (growing phase, during the dry and dry/rainy transition seasons, from July to December) or $2.0 \mathrm{~kg} / \mathrm{d}$ (finishing phase, in the rainy and transition rainy/dry seasons, from January to late April) were supplied per animal. Supplements were formulated to change the protein profile for each plot. Thus, crude protein (CP) content was changed during the lactation phase and the participation of nonprotein N (NPN) in isonitrogenous concentrate varied in the other phases. Therefore, supplements supplied for each one of the plots had 32, 25 and 9.5\% of CP in the lactation phase; and 67, 40 and 13\% of NNP in a total of 36 and $27 \%$ of $\mathrm{CP}$ in the growing and finishing phases, respectively. Animals in the fourth plot received only mineral supplement ad libitum. Every 28 days, animals were weighed for elaboration of growth curve of live weight without fasting (LW).

Five mathematical models to describe animal growth were evaluated. The first model was a multiphase model which divided animal growth into three phases. The first phase of fast growth corresponded from the rainy/dry transition season to the moment when animal significantly reduced its growth rate due to forage availability limitation in the driest season of the year. The second phase of the model corresponded to the restrict growth phase (the lowest daily growth rate) due to feed shortage, typical in the dry season and the first part of the dry-rainy season in tropical regions. The third phase of the model corresponded to a refeeding growth phase, associated to the end of the dryrainy transition, to the rainy season and to the beginning of the rainy-dry transition season of the following year. Finally, two parameters (“Age 1" and "Age 2") estimated the transition moment between the phases, and consequently, the time of the animals in the experiment to the beginning of the second and third phases. This model can be described by equations [1], [2] and [3].

$$
\begin{aligned}
& \mathrm{LW}=\mathrm{a}+\mathrm{b} * \mathrm{~T} \quad \text { if } \mathrm{T} \leq \text { Age1, } \\
& \mathrm{LW}=\mathrm{a}+\mathrm{b} * \text { Age } 1+\mathrm{c} *(\mathrm{~T}-\text { Age } 1) \\
& \text { if Age } 1<\mathrm{T} \leq \text { Age2, } \\
& \mathrm{LW}=\mathrm{a}+\mathrm{b} * \text { Age } 1+\mathrm{c} *(\text { Age } 2-\text { Age } 1)+\mathrm{d} * \\
& \left(1-\mathrm{e}^{(-\mathrm{k} *(\mathrm{~T}-\text { Age } 2))}\right) \text { if } \mathrm{T}>\text { Age2; }
\end{aligned}
$$

logarithm; and “a”, “b”, “c”, “d”, “k”, “Age1” and “Age2” are the model parameters.

Initial average weight of the animals was used as parameter "a" in this study to reduce the number of parameters to be estimated. The other parameters can be interpreted as: daily weight gain in the first phase (parameter "b"), daily weight gain in the second phase (parameter "c"), the difference between weight at maturity and the weight of the animals at the beginning of the third phase (parameter "d"), and final maturation rate, or weight change in relation to weight at maturity in the third phase (parameter " $k$ ").

Two other models were the linear models. The first one was a first-order linear model (Linear; Eq. [4]), and the second was a data logarithmic transformation model (Logarithmic; Eq. [5]).

The linear models set a direct relationship between LW and the experimental period, based on the initial weight and average weight gain rate during the period. The Logarithmic model evaluates the same relationship, but working with LW data and time logarithmically transformed to consider a reduction in the growth rate per time unit as animal ages (Berg \& Butterfield, 1976).

$\mathrm{LW}=\mathrm{e}+\mathrm{f} * \mathrm{~T}$

$\log \mathrm{LW}=\mathrm{g}+\mathrm{h} * \log \mathrm{T}$ Eq. [5] where LW = live weight of animals without fasting $(\mathrm{kg})$; $\mathrm{T}$ = time in the experiment (days); and "e", " $\mathrm{f}$ ", "g” and "h" are the parameters of the models.

In these models (Eq. [4] and [5]), parameters "e' and "g" can be interpreted as estimates of LW values or Log LW at the beginning of the experiment, respectively. Parameters "f” and "h" are the daily average growth rate of LW or Log LW, respectively.

Two non-linear models, known as Gompertz (Eq. [6]) and Logistic (Eq. [7]) were also evaluated. Those models describe growth considering evenly varied growth rates, and they derive from studies on the growth of different species carried out in the beginning of the $20^{\text {th }}$ century. According to López (2008), this type of model would be the one which best represents growth phenomenon when no limitation is imposed to it.

$\mathrm{LW}=\mathrm{i} * \mathrm{e}^{(-\mathrm{e}(-\mathrm{j} * \mathrm{~T}))}$

$\mathrm{LW}=\mathrm{m} /\left(1+\mathrm{e}^{(-\mathrm{n} * \mathrm{~T})}\right)$

where LW = live weight of the animals without fasting $(\mathrm{kg})$; $\mathrm{T}=$ time in the experiment (days); "e" Log e base; and "i", "j", "m" and "n" are the parameters of the model.

In these models (Eq. [6] and [7]), parameters "i" and " $m$ " can be interpreted as the difference between weight at maturity of the animals and the weight of the animals at the beginning of the experiment, and parameters " $\mathrm{j}$ ” and " $\mathrm{n}$ ”, as 
the average maturation rate during growth, that is, the average growth velocity of the animals in relation to their weight at maturity.

Adjustment of the models and parameter estimation were carried out by using REG (for Linear and Logarithmic models) and NLIN (for Multiphase, Gompertz and Logistic models) procedures of SAS (Statistical Analysis System, version 9.2).

The model adequacy evaluation was followed as discussed by Tedeschi (2006). The linear regression of observed on model predicted values was performed, and the coefficient of determination $\left(\mathrm{r}^{2}\right)$ and the simultaneous $F$-test for identity of parameters ( $\beta 0=0$ and $\beta 1=1$ ) were evaluated. Other testing criteria included the generalized concordance correlation coefficient (CCC), the root of the mean square error of prediction (RMSEP) and the partition of the mean square error of the prediction at medium bias, systematic bias and random error. Finally, comparisons among prediction of models were performed for accuracy using the pairwise mean square error of prediction (pMSEP) analysis (Wallach \& Goffinet, 1989) and for precision using the delta Akaike's information criterion (AIC; Burnham \& Anderson, 2002). All calculations of model adequacy statistics were obtained with the MES - Model Evaluation System (http://nutritionmodels.tamu.edu/mes.htm, College Station, Tx, USA; Tedeschi, 2006).

\section{Results and Discussion}

Evaluation of adequacy of the tested models (Table 1) showed that all models were able to predict variability observed among weight of the animals $\left(\mathrm{r}^{2}>0.86\right)$. Analysis of CCC also showed that all models had good accuracy and precision together, and it was lower than 0.900 only for the Logistic model.

Evaluation of identity test of parameters showed that the models Gompertz, Logarithmic and Logistic generated prediction which could not be accepted as true $(\mathrm{P}<0.01)$. Evaluation of $\mathrm{r}^{2}$ and RMSEP showed that the problem with those models can be more linked to their capacity to predict the exact value of LW of each animal than the variability observed among animals. Whereas those models presented RMSEP ranging from 25 to $34 \mathrm{~kg}$, Multiphase and Linear models presented values of 6.8 and $16.1 \mathrm{~kg}$, respectively. The analysis of the decomposition of the MSEP also showed interesting results. In the first two evaluated models (Multiphase and Linear), almost all deviation observed (more than 99\%) could have been attributed to the random error, not evidencing average or systematic deficiency of the models. In the models Gompertz, Logarithmic and Logistic, from 10 to $21 \%$ of the prediction deviations could have been associated to the systematic bias, i.e., a multiplicative error in the predicted values.

The good adequacy of the Multiphase model was expected inasmuch as it was developed by taking into account forage availability, the main factor influencing grazing beef cattle growth (Paulino, 1999). On the other hand, the good predictive capacity showed by the Linear model could be associated to the short period of evaluated time, in relation to life time of the animals. This behavior was also observed by Waldman et al. (1969) and by Fernandes et al. (2007).

The inadequacy observed in the models Gompertz, Logarithmic and Logistic may be associated to the basic premise of the non-linear models normally used for growth description: a growth rate which admits, at most, one inflexion point over growth. The growth rate in those models may start the growth in accelerated phase (increasing rate), that has a inflexion, making the growth decelerated (decreasing rate) until the animal reaches a weight close to the weight at maturity, when this rate keeps reducing, approaching zero, but never reaching it (asymptotic level).

In those examples, a distortion caused by the pattern predicted by those models during parameter adjustment might have happened due to the occurrence of an accelerated growth phase (corresponding to the second rainy season

Table 1 - Statistics ${ }^{1}$ of adequacy evaluation of prediction models of grazing beef cattle growth

\begin{tabular}{|c|c|c|c|c|c|c|c|c|}
\hline \multirow[t]{2}{*}{ Model $^{2}$} & \multirow[t]{2}{*}{ Number of parameters } & \multirow[t]{2}{*}{$\mathrm{r}^{2}$} & \multirow[t]{2}{*}{$\mathrm{P}$} & \multirow[t]{2}{*}{ CCC } & \multirow[t]{2}{*}{ RMSEP } & \multicolumn{3}{|c|}{ MSEP decomposition (\%) } \\
\hline & & & & & & Mean bias & Systematic bias & Random error \\
\hline Multiphase & 7 & 0.993 & 0.617 & 0.996 & 6.83 & 0.075 & 0.271 & 99.6 \\
\hline Gompertz & 2 & 0.916 & $<0.001$ & 0.945 & 25.0 & 0.169 & 12.3 & 87.6 \\
\hline Logarithimic & 2 & 0.902 & $<0.001$ & 0.936 & 26.7 & 0.034 & 10.3 & 89.6 \\
\hline Logistic & 2 & 0.861 & $<0.001$ & 0.886 & 34.0 & 0.000 & 21.1 & 78.9 \\
\hline
\end{tabular}

$1 \mathrm{r}^{2}=$ coefficient of determination, $P=$ probability associated to $\mathrm{F}$ test for identity of parameters, regression of data observed by the predicted, CCC = correlation concordance coefficient, RMSEP = root mean square error of the prediction and MSEP = mean square error of the prediction.

2 Multiphase, $\mathrm{LW}=\mathrm{a}+\mathrm{b} * \mathrm{~T}$, whereas $\mathrm{T} \leq \mathrm{Age} 1, \mathrm{LW}=\mathrm{a}+\mathrm{b} *$ Age1 $+\mathrm{c} *(\mathrm{~T}-$ Age 1$)$, whereas Age $1<\mathrm{T} \leq \mathrm{Age} 2$, and, $\mathrm{LW}=\mathrm{a}+\mathrm{b} *$ Age $1+\mathrm{c} *($ Age $2-\mathrm{Age} 1)+\mathrm{d} *(1-\mathrm{e}$

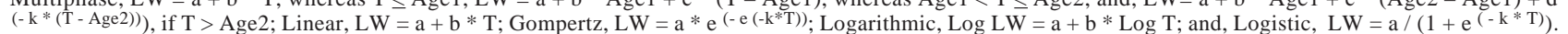


in the life of the animals), after to the feed restriction period, corresponding to the dry season. Because those models do not predict that after an initial accelerated growth and the beginning of growth velocity reduction there could not be a new accelerated growth phase, they might have adjusted a constant decelerated growth rate, which actually represented an average growth rate between decelerated growth in the nutritional restriction period and the accelerated growth of the following rainy season.

This would lead to the overestimation of the animal weight during the restriction phase and to the underestimation of this weight in the re-feeding phase. Then, the effect of the error on the mean deviation would be lowered by error cancellation. This would be consistent with the partition analysis of MSEP presented in this study.

Finally, comparison among the models regarding to accuracy (pMSEP) and precision (AIC) showed significant differences $(\mathrm{P}<0.01)$ among all the models. In both analyses, Multiphase models was superior, followed by the models Linear, Gompertz and Logarithmic. These analyses indicated that among the evaluated models, the Logistic model had the lowest accuracy and precision.

Analysis of prediction error behavior (Figure 1) reinforces the hypotheses presented for the lack of adjustment of the Logarithmic, Gompertz and Logistic models. It can be seen that those models overestimated animal weight in the middle of the assessed growth period, corresponding to the nutritional restriction phase (dry season) in the year. As animals grow (experimental period advances, reaching rainy season following the dry season), models underestimate weights, which become even more extreme when animals get heavier. This is precisely the behavior predicted by the hypothesis previously presented for the lack of adjustment of those models.
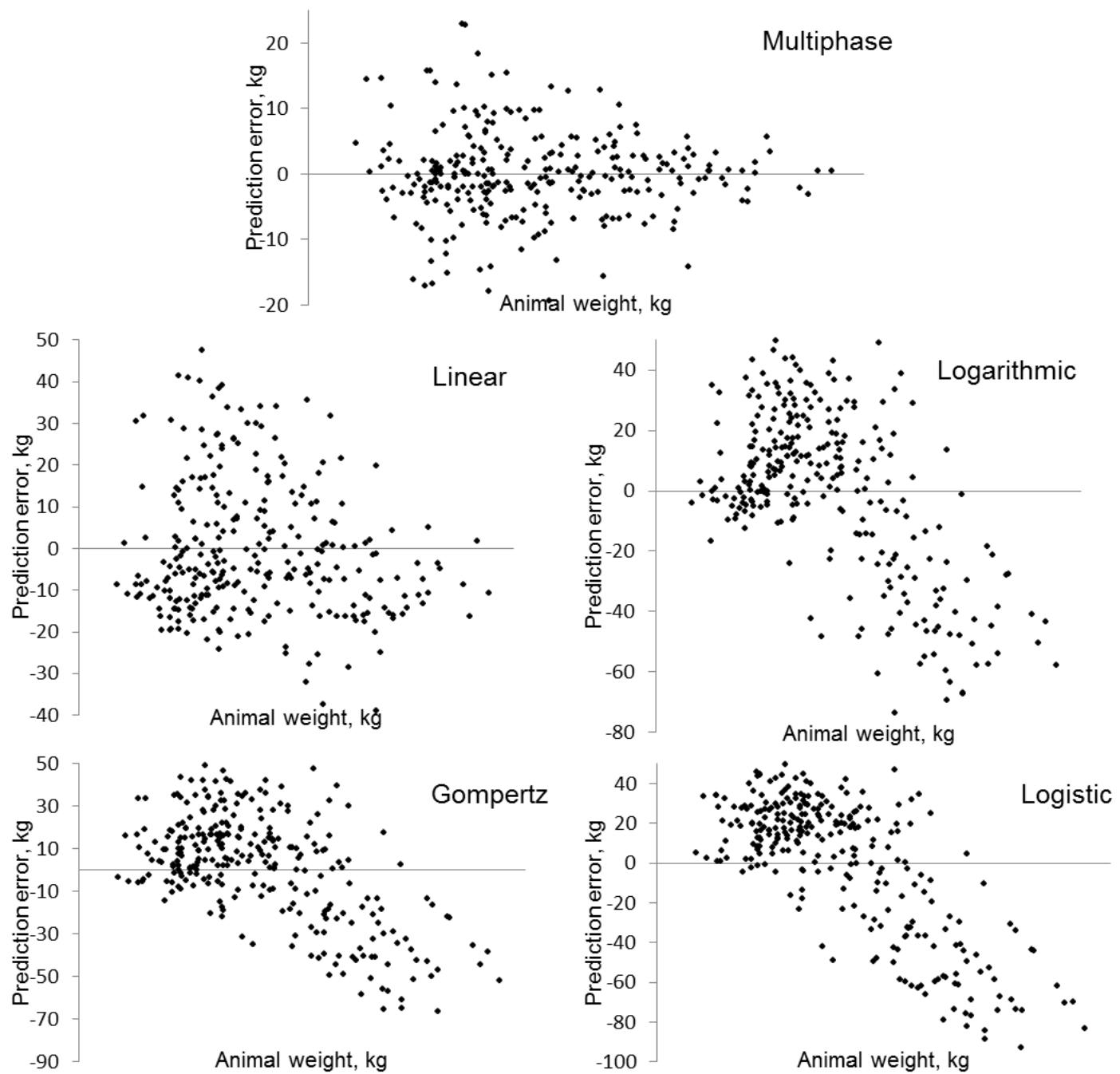

$-100$

Animal weight, kg

Figure 1 - Distribution of the prediction errors of Linear, Logarithmic, Multiphase, Gompertz and Logistic models in function of the animal weight observed. 
Linear and Multiphase models showed lower amplitude of the prediction errors, and more homogeneous distribution. Except for some underestimation points and the trend of reducing errors to greater weights, the Linear model was the one which presented errors more homogenously distributed during all assessed growth stages.

The Multiphase model keeps reducing amplitude of its errors as animals grow, assuming a "funnel shape", rather common in temporal series. However, this deficiency seems to compromise little the efficiency of this model. Even in the early phases, the Multiphase model shows little amplitude of the errors when compared with the Linear model (Figure 1). This reinforces the superiority of the predictions of this model in relation to the others, evidenced by the assessment data (Table 1).

Slight reduction in the growth rate of the animals after weaning (which occurred at 120 days of the experiment) and a drastic reduction in the growth rate after 200 days of experiment were observed (Figure 2). In an annual perspective, the time when this drastic reduction occurred corresponds to September and October. In the region where the experiment was performed, this period of the year can be associated to the end of the dry season and the beginning of dry-water transition period, with the record of the first rainfalls.

According to Paulino et al. (2002), it is exactly at this moment that the lowest weight gains of grazing animals can be expected. This could be associated to the low forage storage, drained by the long dry period and by the physiology of the plants themselves, which start a new cycle from

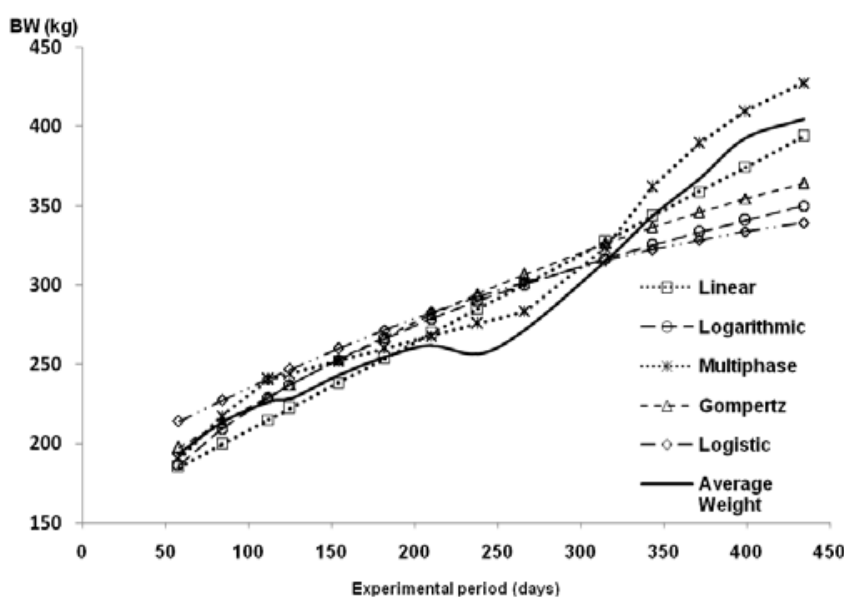

BW = body weight.

Figure 2 - Average weight observed and growth curves projected by means of the parameters estimated for each animal with Linear, Logarithmic, Multiphase, Gompertz and Logistic models. regrowth, changing their composition and reaching a negative carbon balance. This process contributes even more to a reduction in total nutrient availability, aggravated by the rejection of dry forage while the new growth does not have sufficient mass which permits to meet consumption.

The period of great reduction in growth rate lasted barely 50 days, with the growth returning to the high rates after 250 days of experiment. It can be seen, in this period, the greatest deviation presented by the average growth of the animals in comparison with an almost straight line.

Although growth is more intense in the re-feeding period, before 400 days of experiment this inclination was not completely divergent from the initial phase of the growth curve. The observation of this almost linearity of the animal average growth shows a possible reason why other studies have demonstrated a good adjustment of the non-linear growth models in the description of the final shape of the growth curve.

As growth linearity is a typical phenomenon of the short time periods, this indicates that the period of life of the cattle designated for meat production, due to the typical low weight in the Brazilian market, represents a short period in relation to the life of this species.

When growth data on grazing cattle are evaluated for long time periods, as for example in the study on the growth of females by Garnero et al. (2005), it is possible to see that there are seasonal variations but they do not interfere significantly in the shape of the growth curve as a whole. Thus, this curve gets similar to the one predicted by the non-linear models evaluated in this study.

The results observed in this study evidenced that when growth of grazing beef cattle assigned for meat production in Brazilian conditions is evaluated, effects of the short seasonal periods cannot be left out.

The multiphase was the only model able to fit to this deviation of the linear growth, identifying the beginning of the lowest growth phase, close to 100 days of experiment (just before weaning), and the end of this phase, close to 300 days of experiment. This overestimated weights during 200 days of the experiment, but at levels rather lower than the one observed in the predictions of the other models.

Because the linear model does not have curvature, it projected a constant growth during the whole experimental period. At first, this projection underestimates average weight of the animals, then it overestimates it in an intermediate moment and then it underestimates again at the final phase of the experiment. In spite of this, average prediction deviations were small in all the evaluated phases, which was sufficient to make the model show good predictions. 
Superiority of the Linear model on the predictions from models Logarithmic, Logistic and Gompertz was most evident in the final phase of the evaluated growth (Figure 2).

Models Logarithmic, Logistic and Gompertz projected very similar growth curves. Those curves showed a clear incapacity to fit to the growth re-acceleration in the refeeding phase, after reduction of growth velocity in the low forage availability phase. Despite the overestimation of animal weight in the reduced growth phase, the greatest deficiency of those models seemed to be the underestimation of the weight in growth re-acceleration phase with deviation becoming greater and greater as animals grew.

From the shape presented by the average growth curve, it can be inferred that the main cause of lack of adjustment was the failure in estimating the asymptotic weight (weight at maturity) projected by the Logistic and Gompertz models. Indeed, the weights at maturity predicted by these models were 367 and $441 \mathrm{~kg}$, respectively. This did not allow a projection of greater weight for animals at the final phase of the experiment, causing underestimation of the observed weight. Even the weight at maturity estimated by the Multiphase model was smaller than the ones estimated by Garnero et al. (2005) for Nellore females (which ranged from 501 to $553 \mathrm{~kg}$ ).

As the experiment had finished before animals reached maturity, this could have caused underestimation of the weight at maturity by all the models, as discussed by Beltrán et al. (1992). The low final weight presented by the animals supplemented only with mineral might have contributed even more to this limitation.

It is important to emphasize that, in addition to mathematical adequacy of predications made by a model, the information that this model provides about the growth phenomenon under study must be also evaluated.

Thus, Linear and Logarithmic models generated only one set of information on animal growth: average daily growth rate (parameters " $f$ " and " $h$ "). On the other hand, Gompertz and Logistic models were able to estimate weight at maturity (by studying parameters "i" and " $\mathrm{m}$ ", respectively) and the average rate of relative growth during the total period ( parameters “ $\mathrm{j}$ ” and " $\mathrm{n}$ ”).

The Multiphase model allowed to estimate daily absolute growth rate (weight gain) of the first (parameter "b") and second (parameter "c) growth phases, the relative growth rate of the third growth phase (parameter " $k$ ) and the weight at maturity (estimated as: a $+\mathrm{b} *$ Age $1+\mathrm{c} *$ (Age $2-$ Age1) $+\mathrm{d})$.

In addition, parameters "Age 1" and "Age 2" of this model also estimated the moment when animals started to experience nutritional shortage in the low forage availability period, significantly reducing the growth rate, and the moment when animals were able to use the greater availability of nutrients after sprouting of the pastures, significantly increasing growth rate.

This last aspect is very important when it is desired to study production systems on pasture. According to Euclides (2001), in normal field situation, duration of season with feed restriction affects performance of the production system even more than the intensity of the restriction itself.

\section{Conclusions}

The Multiphase model was more efficient than the others in all aspects of description of the growth of the grazing beef cattle, assigned to slaughter in tropical conditions. Other multiphase models should be studied to define the most proper ones for each production condition and for the objectives of each study.

\section{References}

AGRICULTURAL RESEARCH COUNCIL - ARC. The nutrient requirements of ruminant. Slough: Livestock, Commonwealth Agriculture Bureaux, 1980. 351p.

BELTRÁN, J.J.; BUTTS JUNIOR, W.T.; OLSON, T.A. et al. Growth patterns of two lines of angus cattle selected using predicted growth parameters. Journal of Animal Science, v.70, p.734-741, 1992 .

BERG, R.T.; BUTTERFIELD, R.M. New concepts of cattle growth. Sydney: Sydney University Press, 1976. 240p.

BURNHAM, K.P.; ANDERSON, D.R. Model selection and multimodel inference: a practical information-theoretic approach. 2.ed. New York: Springer-Verlag, 2002. 488p.

EUCLIDES, V.P.B. Produção intensiva de carne bovina em pasto. In: SIMCORTE - SIMPÓSIO DE PRODUÇÃO DE GADO DE CORTE, 2., 2001, Viçosa, MG. Anais... Viçosa, MG: UFV, DZO, 2001. p.55-82.

FERNANDES, H.J.; PORTO, M.O.; AZEVEDO, J.A.G. et al. Biometria de bezerros de corte a pasto. In: REUNIÃO ANUAL DA SOCIEDADE BRASILEIRA DE ZOOTECNIA, 44., 2007, Jaboticabal. Anais... Jaboticabal: Sociedade Brasileira de Zootecnia, [2007]. (CD-ROM).

GARNERO, A.V.; MARCONDES, C.R.; BEZERRA, L.A.F. et al. Parâmetros genéticos da taxa de maturação e do peso assintótico de fêmeas da raça Nelore. Arquivos Brasileiros de Medicina Veterinária e Zootecnia, v.57, p.652-662, 2005.

LAWRENCE, T.J.; FOWLER, V.R. Growth of farm animals 2.ed. Wallingford: CAB International, 2002. 347p.

LÓPEZ, S. Non-Linear functions in animal nutrition. In: FRANCE, J.E.; KEBREAB, E. (Eds.) Mathematical modeling in animal nutrition. Oxfordshire: CABI, 2008. 574p.

PAULINO, M.F. Estratégias de suplementação para bovinos em pastejo. In: SIMCORTE - SIMPÓSIO DE PRODUÇÃO DE GADO DE CORTE, 1., 1999, Viçosa, MG. Anais... Viçosa, MG: UFV, DZO, EJZ, 1999. p.137-156.

PAULINO, M.F.; ZERVOUDAKIS, J.T.; MORAES, E.H.B.K. et al. Bovinocultura de ciclo curto em pastagens. In: SIMCORTE - 
SIMPÓSIO DE PRODUÇÃO DE GADO DE CORTE, 3., 2002, Viçosa, MG. Anais... Viçosa, MG: UFV, 2002. p.153-196.

TEDESCHI, L.O. Assessment of the adequacy of mathematical models. Agricultural Systems, v.89, p.225-247, 2006.

THORNLEY, J.H.M.; FRANCE, J. Mathematical models in agriculture: quantitative methods for the plant, animal and ecological sciences. 2.ed. Oxon: CABI, 2007. 906p.
WALDMAN, R.C.; TYLER, W.J.; BRUNGARDT, V.H. Estimation of body composition in young calves. Journal of Animal Science, v.29, p.426-428, 1969.

WALLACH, D.; GOFFINET, B. Mean squared error of prediction as a criterion for evaluating and comparing system models. Ecological Modeling, v.44, p.299-306, 1989. 